\title{
Diabetes Self-Efficacy and Associated Factors among People Living with Diabetes in Ibadan, Southwestern Nigeria
}

\author{
Lucia Y. Ojewale, Elizabeth A. Okoye, and Odinaka B. Ani
}

\section{ABSTRACT}

With the increasing prevalence of diabetes mellitus (DM) globally, including in Nigeria, self-care practices are universally recognized as imperative to keeping the illness under control and preventing complications. It is important to determine how competent patients feel about managing their diabetes, as well as their psychosocial adjustment. Self-efficacy measures these important aspects of diabetes care and act as a guide to health professionals on how best to tailor diabetes education and support. There is a dearth of studies on self-efficacy and associated influences, among people living with diabetes in Nigeria. Hence, this study was carried out to fill the lacunae. This descriptive study was carried out at the Out-patient Clinic of the University College Hospital (UCH), Ibadan, among 235 people receiving diabetes treatment. A total sampling of all available patients who provided consent at the time of data collection was done. The instrument for data collection was a questionnaire consisting of a section on sociodemographic and clinical characteristics including fasting blood glucose; followed by a section on diabetes self-efficacy. Diabetes self-efficacy was measured using the validated and adapted Michigan Diabetes Empowerment scale (DES). Ethical approval was obtained from the University of Ibadan/University College Hospital Institutional Review Board (UI/UCH IRB). Data were entered into the Statistical Package for Social Sciences, version 20 and analysed using frequencies, percentages, mean, independent t-test and Pearson's correlation at $\alpha \mathbf{0 . 0 5}$. Participants were predominantly women $(60.9 \%)$ and had a mean age of $59.3 \pm 14.0$ years. More than half of the participants $(55 \%)$ had a high self-efficacy level. Educational level and having a family member who is a nurse, or a doctor were significantly associated with high self-efficacy. Fasting blood glucose level was negatively correlated with self-efficacy and the domain of managing the psychological aspect of diabetes. In conclusion, the study showed that a good percentage of people living with diabetes had high self-efficacy, which was influenced by educational level and having a health professional as a relative. Those with high self-efficacy had better glucose control. It is recommended that individually tailored diabetes education and support be provided for people with poorly controlled glucose level, to improve their self-efficacy.

Keywords: Glucose-control, self-care, self-efficacy, type 2 diabetes mellitus.
Submitted : November 3, 2021

Published : December 24, 2021

ISSN: 2593-8339

DOI: $10.24018 /$ ejmed.2021.3.6.1129

L. Y. Ojewaler*

Department of Nursing, Faculty of Clinical Sciences, University of Ibadan, Nigeria.

(e-mail: luciayetunde@gmail.com)

E. A. Okoye

Department of Nursing, Faculty of Clinical Sciences, University of Ibadan, Nigeria.

(e-mail: okoyeelizabeth98@gmail.com) O. B. Ani

Royal Berkshire NHS Foundation Trust, Reading, England.

(e-mail: aniodinaka@gmail.com)

*Corresponding Author

\section{INTRODUCTION}

Diabetes mellitus (DM) was termed 'the fastest growing global health emergency' by the International Diabetes Federation, in 2019 [1]. The federation further stated that the 463 million cases reported globally in 2019 were expected to increase by $51 \%$ in 2045 ; with a much higher increase of $143 \%$ expected in Africa. A high prevalence of DM complications including kidney failure, heart attack, erectile dysfunction and other cardiovascular complications has also been reported among Nigerians [2].

Diabetes self-care activities are behaviors undertaken by people with diabetes to successfully manage the disease on their own [3]. These activities include self-monitoring blood glucose, making healthy lifestyle choices (healthy eating, physical activity, tobacco cessation and weight management, taking and managing medications, preventing diabetes complications (self-monitoring of foot health; active participation in screening for eye, foot, and renal complications; and immunizations), and setting self-selected behavioural goals [4]. It has been established in the literature that many benefits result for patients and even health care personnel when patients are well involved in their own care [5], [6]. Self-care practices in people living with diabetes are thus essential to keeping the illness under control and forestalling complications [3].

A major influencer of self-care is self-efficacy [7]. This is because individuals who are self-motivated and feel capable of adopting lifestyle changes required by a chronic illness 
such as diabetes tend to achieve better glucose control compared to those with poor self-efficacy [8].

Self-efficacy emanated from Bandura's social cognitive theory, as one of the five constructs [9]. It is the belief individuals have in their competencies, especially the ability to overcome difficulties ahead and complete a task [4]. It has been linked to positive outcomes in people with chronic health conditions, which require a life-long treatment [10]. In diabetes management, self-efficacy is a key component that is required for both the initiation and continuation of proper self-care activities. A self-efficacious diabetes patient will therefore make conscious and continuous efforts to perform prescribed lifestyle modifications, among other activities [11].

Among factors that influence self-efficacy is diabetes education which positively improves self-efficacy [9]. Also, some authors [11], [12] asserted that higher educational status had a positive influence on self-efficacy. Other predictors of high self-efficacy include positive mental attitude, family support, employment status, longer duration of diabetes and older age [13].

In measuring self-efficacy, particular attention needs to be paid to the psychosocial aspect as it tends to have a high impact on blood glucose control [14]. Psychosocial aspects of self-efficacy include the ability to cope with diabetesassociated stress, getting social support, motivating self to manage diabetes, and deciding on the best way to manage the condition. Without this important cornerstone, effective glucose control is often difficult, [15]. Unfortunately, these aspects are often neglected and under-researched, as opined by Nicolucci et al. [15] in a large study that involved 17 countries in four continents.

Studies on the self-efficacy of people with diabetes are scarce in Nigeria. In addition, to the best of our knowledge, no study has correlated self-efficacy with glycaemic control and identified other factors that could influence patients' selfefficacy.

We hypothesized that there is a negative linear relationship between the fasting blood glucose and the diabetes selfefficacy of the patients. We also hypothesized that patient characteristics are associated with their self-efficacy.

\section{MATERIALS AND MethoD}

\section{A. Study Design, Setting and Population}

This study adopted a cross-sectional research design. It was conducted at the diabetes clinic of the medical outpatient unit of the University College Hospital (UCH), Ibadan. The hospital is situated in Oritamefa, which is in Ibadan North Local Government Area, of Oyo State, Southwest, Nigeria. The University College Hospital is the first tertiary hospital in Nigeria and was established in 1952. It was modelled after the University College Hospital, London. The UCH is affiliated with the first Nigerian tertiary education institution. Besides being a healthcare providing institution, it is a centre for research and training and a referral centre for Secondary Health Care facilities. The diabetes clinic holds every Monday with an average population of fifty (50) patients.

The study population was type $2 \mathrm{DM}$ patients receiving treatment at the diabetes clinic of the UCH. Eligibility criteria included having been diagnosed with Type 2 diabetes at least one month before data collection, and neither cognitively nor visually impaired.

\section{B. Instrument for Data Collection}

A self-administered questionnaire was used as a tool for obtaining data. It was made up of three (3) sections: A to C. Section A contained questions that elicited the sociodemographic data of the respondents, based on the literature review. Fasting blood glucose (FBG) was recorded in the same section. Respondents' FBG values were checked using the Accucheck glucometer at the clinic laboratory.

Section B contained questions that assessed the patient's self-efficacy, while Section C contained questions that assessed the factors influencing the patient's self-efficacy levels. The Self-efficacy Questionnaire was developed by the University of Michigan Diabetes Research and Training Center, in the year 2000, [16] and permission for its use was obtained by the lead author of this paper. The scale is divided into three subscales which are 'managing the psychosocial aspects of diabetes' (9 items), 'assessing dissatisfaction and readiness to change' ( 9 items), and 'setting and achieving diabetes goals' (10 items). The scoring of the DES is straightforward and is based on completed items. An item checked "strongly agree" receives 5 points; "agree" -4 points; "neutral" -3 points; "disagree" -2 points; and "strongly disagree" 1 point. To get the score for each of the subscales, each participants' total score for the subscale, i.e., the numerical value is added up and divided by the number of items in the subscale. For instance, the psychosocial aspect of diabetes management consists of 9 items. The total subscale score is added up and divided by 9 . In addition, the DES overall score can be obtained by totaling up all the item scores and dividing by 28 . The validity of the self-efficacy scale, both face and content, was established by the lead author of this study who has been involved in diabetes research for several years. The reliability of the questionnaire was established with an alpha of 0.96 for the entire scale and 0.93 , 0.81 ; and 0.91 , respectively for the three aforementioned subscales.

\section{Sampling and Data Collection Procedure}

Following ethical approval, the permission of the University College Hospital management was obtained. Patients were met at the medical outpatient department, having been introduced by the nurses in charge of the clinic. Informed consent was then sought and obtained from patients who wanted to participate in the study. The questionnaire was both self-and interviewer-administered, in the case of nonliterate patients. All patients who were eligible and gave their consent participated. The data collection lasted for three months.

\section{Method of Data Analysis}

Data obtained was cleaned, coded and entered into the IBM-SPSS version 20. Descriptive statistics of frequency counts, simple percentages, mean, and standard deviation were used to summarize and present results. Independent ttest and Analysis of Variance (ANOVA) were used to compare the mean scores in the different sociodemographic/personal characteristics of the patients.

The total self-efficacy score was further dichotomized 
based on the mean scores to determine participants with high or low self-efficacy. Participants' fasting blood glucose (FBG) was categorised as normal and high based on the World Health Organisation (2006) cut-off point of $110 \mathrm{mg} / \mathrm{dl}$.

Pearson Product moment correlation was used in determining the association between fasting blood glucose and self-efficacy score. We considered p-values less than 0.05 to be statistically significant.

\section{E. Ethical Consideration}

Ethical approval was obtained before the commencement of the research from the University of Ibadan/University College Hospital Institutional Review Board (UI/UCH IRB) with approval number UI/EC/19/0290. The purpose of the study, with the assurance of confidentiality and anonymity of all information given by respondents, were included in the consent form and explained verbally to the patients.

\section{Results}

A total of two hundred and thirty-five (235) patients participated in the study with the majority being female (60.9\%). As shown in Table I, the predominant religion was Christianity practised by $66.8 \%$ of the participants. About half of the participants $(51.1 \%)$ were diagnosed with diabetes less than 7 years before data collection, while a little over a fifth of all the participants $(22.6 \%)$ had a spouse or child who is a health professional." Other characteristics are presented on Table I.

As shown in Fig. 1, the proportion of those with selfefficacy and those without were about the same $(55 \%$ vs $45 \%)$.

Table II shows that the level of education and having a family member who is a health professional was associated with self-efficacy, $(\mathrm{p}<0.05)$. Post Hoc analysis showed a better self-efficacy among those with no formal education.

Two third $(66.8 \%)$ of the patients had well-controlled blood glucose level. This is presented in Fig. 2. Furthermore, as shown in Table III, patients with normal glucose control had a significantly higher self-efficacy score compared to those with suboptimal glucose control.

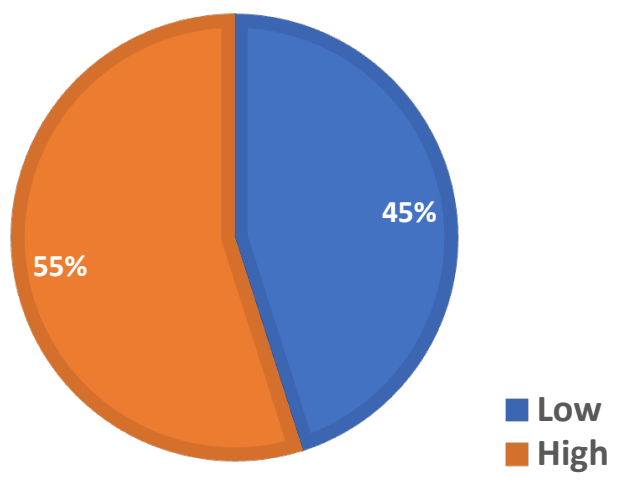

Fig. 1. Categories of diabetes self-efficacy. A little over half had well controlled glucose level.
TABLE I: SOCIO-DEMOGRAPHIC CHARACTERISTICS OF PATIENTS

\begin{tabular}{|c|c|c|c|}
\hline Variable & Categories & $f(n=235)$ & $\%$ \\
\hline \multirow{4}{*}{$\begin{array}{c}\text { Age (in years) } \\
\text { mean }( \pm) \\
59.3(14.0)\end{array}$} & $16-35$ & 15 & 6.4 \\
\hline & $36-55$ & 64 & 27.2 \\
\hline & $56-75$ & 133 & 56.6 \\
\hline & $75-95$ & 23 & 9.8 \\
\hline \multirow{3}{*}{ Religion } & Christianity & 157 & 66.8 \\
\hline & Islam & 77 & 32.8 \\
\hline & Traditionalist & 1 & 0.3 \\
\hline \multirow{5}{*}{$\begin{array}{l}\text { Highest level of } \\
\text { education }\end{array}$} & No formal education & 29 & 12.3 \\
\hline & Primary school & 52 & 22.1 \\
\hline & Secondary school & 64 & 27.2 \\
\hline & Tertiary education & 73 & 31.1 \\
\hline & Post-graduate education & 17 & 7.2 \\
\hline \multirow{2}{*}{ Sex } & Male & 92 & 39.1 \\
\hline & Female & 143 & 60.9 \\
\hline \multirow{2}{*}{$\begin{array}{c}\text { Year of medical } \\
\text { diagnosis } \\
\text { Mean } \pm 9.5 \pm 8.34\end{array}$} & $\leq 7$ years & 120 & 51.1 \\
\hline & $>7$ years & 115 & 48.9 \\
\hline \multirow{2}{*}{$\begin{array}{c}\text { Spouse or Child } \\
\text { a health } \\
\text { professional? }\end{array}$} & Yes & 53 & 22.6 \\
\hline & No & 182 & 77.4 \\
\hline \multirow{4}{*}{ Marital status } & Married & 166 & 70.6 \\
\hline & Single & 12 & 5.1 \\
\hline & Divorced/Separated & 11 & 4.7 \\
\hline & Widowed & 46 & 19.6 \\
\hline \multirow{2}{*}{$\begin{array}{c}\text { Have a } \\
\text { glucometer? }\end{array}$} & Yes & 187 & 79.6 \\
\hline & No & 48 & 20.4 \\
\hline
\end{tabular}

Most of the participants were over 50 years of age. About a quatre of them had a relative in the health profession.

TABLE II: ASSOCIATION BETWEEN PATIENT CHARACTERISTICS AND SELFEFFICACY

\begin{tabular}{|c|c|c|c|c|}
\hline Variable & $\mathrm{n}$ & $\begin{array}{c}\text { Mean } \\
\operatorname{DES}( \pm)\end{array}$ & $\begin{array}{c}\mathrm{t}- \\
\text { value }\end{array}$ & p-value \\
\hline Sex: Male & 92 & $4.1(0.56)$ & 1.084 & 0.279 \\
\hline Female & 143 & $4.1(0.51)$ & & \\
\hline \multicolumn{5}{|l|}{ Marital status: } \\
\hline Married & 166 & $4.2(5.1)$ & 1.229 & 0.220 \\
\hline Not married & 69 & $4.1(0.58)$ & & \\
\hline \multicolumn{5}{|l|}{ Age } \\
\hline $16-35$ years & 15 & $4.2(0.48)$ & 0.300 & 0.767 \\
\hline $36-55$ & 64 & $4.1(0.57)$ & & \\
\hline $56-75$ & 133 & $4.13(0.53)$ & & \\
\hline 76-95 & 23 & $4.3(0.47)$ & & \\
\hline \multicolumn{5}{|l|}{ Religion: } \\
\hline Christianity & 157 & $4.1(0.53)$ & -0.203 & 0.836 \\
\hline Islam & 77 & $4.2(0.52)$ & & \\
\hline Traditional & 1 & 3.7 & & \\
\hline \multicolumn{5}{|l|}{$\begin{array}{c}\text { Educational } \\
\text { level: }\end{array}$} \\
\hline $\begin{array}{l}\text { No formal } \\
\text { educ. }\end{array}$ & 29 & $4.1(0.47)$ & 2.752 & $0.029 *+$ \\
\hline Primary & 52 & $4.3(0.46)$ & & \\
\hline Secondary & 64 & $4.1(0.52)$ & & \\
\hline Tertiary & 73 & $4.1(0.53)$ & & \\
\hline Postgraduate & 17 & $4.2(0.74)$ & & \\
\hline \multicolumn{5}{|l|}{$\begin{array}{l}\text { Ownership of a } \\
\text { glucometer: }\end{array}$} \\
\hline Yes & 187 & $4.1(0.54)$ & -0.188 & 0.851 \\
\hline No & 48 & $4.2(0.50)$ & & \\
\hline \multicolumn{5}{|l|}{$\begin{array}{l}\text { Diabetes } \\
\text { duration: }\end{array}$} \\
\hline$\leq 7$ years & 120 & $4.1(0.56)$ & -0.258 & 0.796 \\
\hline$>7$ years & 115 & $4.2(0.51)$ & & \\
\hline \multicolumn{5}{|l|}{$\begin{array}{l}\text { Spouse or child } \\
\text { a health care } \\
\text { worker }\end{array}$} \\
\hline Yes & 53 & $4.3(0.50)$ & 2.380 & $0.018^{*}$ \\
\hline No & 182 & $4.1(0.53)$ & & \\
\hline
\end{tabular}

* significant at $\mathrm{p}<0.05$.

+ Post-Hoc analysis shows that people with primary education had a significantly higher self-efficacy score compared to those with secondary and tertiary education, at $\mathrm{p}<0.01$. 


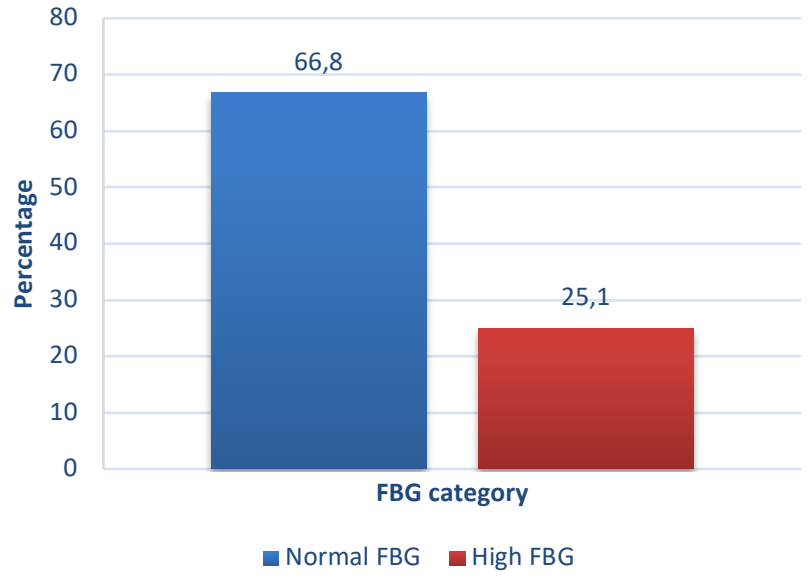

Fig. 2. Blood glucose category. Many of the patients had a normal glucose level.
TABLE III: INDEPENDENT T-TEST SHOWING THE RELATIONSHIP BETWEEN DiABETES SELF-EFFICACY AND FASTING BLOOD GLUCOSE VALUE

\begin{tabular}{ccccc}
\hline \hline FBG category & $\mathrm{n}$ & mean DES $( \pm)$ & t-value & p-value \\
\hline \hline Normal FBG & 157 & $4.29(0.51)$ & 2.430 & 0.016 \\
High & 59 & $4.00(0.60)$ & & \\
\hline \hline
\end{tabular}

Normoglycaemic patients had a significantly higher self-efficacy score than those with high fasting blood glucose, $\mathrm{p}<0.05$.

Table IV shows the result of the correlation between the main and three subscales of diabetes self-efficacy and fasting blood glucose. There was a moderate negative correlation between fasting blood glucose and diabetes self- efficacy; $r$ $(233)=-0.14, p=0.042$, so also between managing the psychosocial aspect of diabetes and FBG, $r(223)=-0.159$, p $=0.020$.

TABLE IIV: RELATIONSHIP BETWEEN PARTICIPANTS’ FASTING BLOOD GLUCOSE AND SELF-EFFICACY DOMAINS

\begin{tabular}{cccccccc}
\hline \hline Total Diabetes self-efficacy & $\begin{array}{c}\text { Managing the } \\
\text { psychosocial aspects } \\
\text { of diabetes }\end{array}$ & $\begin{array}{c}\text { Assessing Dissatisfaction and } \\
\text { Readiness to Change }\end{array}$ & Setting and achieving diabetes goals \\
\hline Coef. & $\begin{array}{c}\mathrm{p}- \\
\text { value }\end{array}$ & Coef. & $\mathrm{p}$ - value & Coef. & p- value & Coef & \\
\hline$-0.139^{*}$ & 0.042 & $-0.159^{*}$ & 0.020 & -0.092 & 0.176 & -0.132 & 0.052 \\
\hline \hline
\end{tabular}

Correlation is significant at the 0.05 level (2-tailed). There was a moderate negative correlation between Fasting blood glucose and diabetes selfefficacy; $\mathrm{r}(233)=-0.14, \mathrm{p}=0.042$, so also between managing the psychosocial aspect of diabetes and FBG, $\mathrm{r}(223)=-0.159, \mathrm{p}=0.020$.

\section{DiscusSION}

The diabetes self-efficacy and associated factors were examined among diabetes patients attending the medical outpatient unit of a teaching hospital in southwest Nigeria. The mean age of the patients was 59 years, showing a preponderance of diabetes in older people as previously highlighted [17].

The majority of the participants $(87.7 \%)$ had received at least a basic formal education (primary school education). This can be attributed to the urban community (Ibadan metropolis) where the study took place. In the Ibadan community, education is highly valued and that is why basic primary education is encouraged for both males and females. It is important to note that people with primary school education had a significantly higher level of self-efficacy compared to other participants, excluding those with postgraduate degrees. This is contrary to the findings of other authors [18], [19]. Our finding in this area could be because people with basic education have enough intelligence to understand and obey what diabetes management requires without over questioning issues related to the management.

Another interesting finding in this study is the role of family members of people with diabetes mellitus in promoting the self-efficacy of such individuals. Having a family member who is a core health care professional significantly improved the self-efficacy of the participants in this study. Previous authors [20], [21], have documented the positive impact of supportive and knowledgeable family members in improving the self-efficacy of people with diabetes. Having a family member who is a health care professional, thereby possessing knowledge of diabetes or teaching family members about diabetes ultimately produce positive results. The former is the case in this study.
Self-efficacy which has been defined as a core belief related to an individual's own perceived ability to undertake or maintain certain actions to achieve desired outcomes, [22], was found to be high as more than half of the participants had scores above the average. Generally, participants in this study had better self-efficacy scores, when compared to those who participated in studies conducted in other countries, [17], [23]-[25]. On the other hand, the self-efficacy score is similar to that reported among patients in Malaysia [26]. Different instruments were however used in the various studies.

Age, gender and disease duration were not associated with the self-efficacy of the participants in the present study. This is unlike what was reported by some past authors, [15], [17], [24], [27].

In this study, the fasting blood glucose level of the patients significantly influenced the self-efficacy level. There was a negative correlation between the fasting blood glucose and self-efficacy of the participants. Patients with high (poorly controlled) blood glucose, had lower self-efficacy. This is similar to the findings of other authors [20], [26] among Thai and Malaysian patients, respectively. This is not too surprising. As stated by Bandura, [22] 'self-efficacy refers to an individual's belief in his or her capacity to execute behaviors necessary to produce specific performance attainments. Patients who believed they could not manage their diabetes by themselves or adopt lifestyle changes did indeed suffer from poor glucose control. These individuals have to be identified and offered special support that would enhance their self-efficacy. Interventions to support selfefficacy include setting realistic goals, self-talk and motivation, use of peer models, teaching patients' skills (which they perceive they lack), [28]. This requires a health care system that is attuned to incorporating psychosocial influences on clinical outcomes of patients with diabetes. 
Regrettably, many countries in Africa suffer from a poor health system that is still struggling with the scourge of communicable diseases, [29].

There was also a negative correlation between fasting blood glucose and self-efficacy in managing the psychosocial aspects of diabetes. This means that patients who were highly efficacious in managing the psychosocial aspects of diabetes had lower (better) glycaemic control. The influence of a patient's sense of wellbeing or positive psychological state on effective blood glucose control has been demonstrated by several authors [20], [21], [30] among patients within and outside Africa.

\section{CONCLUSION}

The diabetes self-efficacy level of patients in this study was slightly better than that of patients in other developing countries. It was influenced by educational level and having a family member who is in a health-related discipline, underscoring the importance of well-enlightened family members. Also, poor self-efficacy particularly in the domain of managing the psychosocial aspect of the condition had a negative influence on blood glucose control. Individualized measures must be put in place to improve the self-efficacy level of patients with diabetes. Family members can be great allies of health care professionals in achieving this aim. Educational talks and programs can be intensified in clinical settings to boost the self-efficacy levels of patients at the initial stages of their disease. This would make them believe in themselves and manage the disease better on their own.

\section{ACKNOWLEDGMENT}

The authors wish to acknowledge the following people who contributed in one way or another to the study:

- Study participants at the Outpatient Clinic of the University College Hospital, Ibadan, Nigeria.

- Staff nurses and medical doctors at the diabetes clinic.

\section{FUNDING}

Authors received no funding for this study.

\section{CONFLICT OF INTEREST}

Authors declare that they do not have any conflict of interest.

\section{REFERENCES}

[1] International Diabetes Federation. IDF Diabetes Atlas. 7th ed. [Internet] 2015. Available from:

https://www.diabetesatlas.org/upload/resources/previous/files/7/IDF\% 20Diabetes\%20Atlas\%207th.pdf.

[2] Agofure O, Okandeji-Barry OR, Ogbon P. Pattern of diabetes mellitus complications and co-morbidities in ughelli north local government area, Delta State, Nigeria. Nigerian Journal of Basic and Clinical Sciences. 2020; 17(2): 123.

[3] Bonger Z, Shiferaw S, Tariku EZ. Adherence to diabetic self-care practices and its associated factors among patients with type 2 diabetes in Addis Ababa, Ethiopia. Patient Preference and Adherence. 2018; 12: 963 .
[4] Akhtar M. What is self-efficacy? Bandura's 4 sources of efficacy beliefs. Positive psychology UK. 2008.

[5] Shrivastava R, Shrivastava S, Ramasamy J. Role of self-care in management of diabetes mellitus. Journal of Diabetes and Metabolic Disorders. 2013; 12(1): 12-4.

[6] Alyaemni A. Sociodemographic factors associated with diabetes selfcare activities at a primary healthcare center in Riyadh: An analytical cross-sectional study. POJ Diabetes Obes. 2019; 1(1): 1-9.

[7] Mishali M, Omer H, Heymann AD. The importance of measuring selfefficacy in patients with diabetes. Family practice. $2011 ; 28(1)$ : 82-7.

[8] Beckerle CM, Lavin MA. Association of self-efficacy and self-care with glycemic control in diabetes. Diabetes Spectrum. 2013; 26(3): 172-8.

[9] LaMorte WW. Diffusion of Innovation Theory. [Internet] 2016 [Updated 2018 Jan 25, cited 2021 Jul 18]. Available from: http://sphweb.bumc.bu.edu/otlt/MPH-

[10] Ebrahimi Belil F, Alhani F, Ebadi A, Kazemnejad A. Self-efficacy of people with chronic conditions: A qualitative directed content analysis. Journal of Clinical Medicine. 2018; 7(11): 411.

[11] Amer FA, Mohamed MS, Elbur AI, Abdelaziz SI, Elrayah ZA. Influence of self-efficacy management on adherence to self-care activities and treatment outcome among diabetes mellitus type 2 . Pharmacy Practice (Granada). 2018; 16(4).

[12] Hailu FB, Moen A, Hjortdahl P. Diabetes self-management education (DSME)-Effect on knowledge, self-care behavior, and self-efficacy among type 2 diabetes patients in Ethiopia: A controlled clinical trial. Diabetes, Metabolic Syndrome and Obesity: Targets and Therapy. 2019; 12: 2489.

[13] Messina R, Rucci P, Sturt J, Mancini T, Fantini MP. Assessing selfefficacy in type 2 diabetes management: validation of the Italian version of the Diabetes Management Self-Efficacy Scale (IT-DMSES). Health and Quality of Life Outcomes. 2018; 16(1): 1-9.

[14] Kalra S, Jena BN, Yeravdekar R. Emotional and psychological needs of people with diabetes. Indian Journal of Endocrinology and Metabolism. 2018; 22(5): 696.

[15] Nicolucci A, Burns KK, Holt R, Comaschi M, Hermanns N, Ishii H, et al. Educational and Psychological Issues Diabetes Attitudes, Wishes and Needs second study (DAWN2TM): Cross-national benchmarking of diabetes-related psychosocial outcomes for people with diabetes. Diabet Med. 2013; 30: 767-7.

[16] University of Michigan Diabetes Research and Training Center. Diabetes Attitude Questionnaire.

[17] Ojewale LY, Oluwatosin AO, Fasanmade AA, Odusan O. A survey on patients' characteristics, perception of family support and diabetes selfmanagement among type 2 diabetes patients in South-West Nigeria. Nursing Open. 2019; 6(2): 208-15.

[18] Pawar SS, Thakurdesai PA. Quality of life with type 2 diabetes: translation and validation of Indian version of DES-5. International Journal of Life Sciences Biotechnology and Pharma Research 2013. [Internet] 2013. Available from:

http://www.ijlbpr.com/index.php? $\mathrm{m}=$ content $\& \mathrm{c}=$ index \&a=show\&cati $\mathrm{d}=119 \& \mathrm{id}=274$.

[19] Tol A, Baghbanian A, Mohebbi B, Shojaeizadeh D, Azam K, Shahmirzadi SE, et al. Empowerment assessment and influential factors among patients with type 2 diabetes. Journal of Diabetes \& Metabolic Disorders. 2013; 12(1): 1-5.

[20] Wichit N, Mnatzaganian G, Courtney M, Schulz P, Johnson M. Randomized controlled trial of a family-oriented self-management program to improve self-efficacy, glycemic control and quality of life among Thai individuals with Type 2 diabetes. Diabetes Research and Clinical Practice. 2017; 123: 37-48.

[21] Pamungkas RA, Chamroonsawasdi K, Vatanasomboon P. A systematic review: family support integrated with diabetes self-management among uncontrolled type II diabetes mellitus patients. Behavioral Sciences. 2017; 7(3): 62 .

[22] Bandura A. Regulation of cognitive processes through perceived selfefficacy. Developmental Psychology. 1989; 25(5): 729.

[23] Rivera-Hernandez M. Depression, self-esteem, diabetes care and selfcare behaviors among middle-aged and older Mexicans. Diabetes Research and Clinical Practice. 2014; 105(1): 708.

[24] Devarajooh C, Chinna K. Depression, distress and self-efficacy: The impact on diabetes self-care practices. PloS One. 2017; 12(3): e0175096.

[25] Calli D, Kartal A. The relationship between self-efficacy of diabetes management and well-being in patients with type 2 diabetes. Nigerian Journal of Clinical Practice. 2021; 24(3): 393.

[26] Tharek Z, Ramli AS, Whitford DL, Ismail Z, Zulkifli MM, Sharoni SK, et al. Relationship between self-efficacy, self-care behaviour and glycaemic control among patients with type 2 diabetes mellitus in the 
Malaysian primary care setting. BMC Family Practice. 2018; 19(1): 110.

[27] Xu XY, Leung AY, Chau PH. Health literacy, self-efficacy, and associated factors among patients with diabetes. HLRP: Health Literacy Research and Practice. 2018; 2(2): e67-77.

[28] Kirk, K. Self-efficacy: helping students believe in themselves. [Internet] Available from: https://serc.carleton.edu/NAGTWorkshops/affective/efficacy.html.

[29] https://www.afro.who.int/sites/default/files/2017-06/african regional _health_report2006_0.pdfhttps://www.afro.who.int/sites/default/files/ 2017-06/african regional health report2006 0.pdf

[30] Akpalu J, Yorke E, Ainuson-Quampah J, Balogun W, Yeboah K. Depression and glycaemic control among type 2 diabetes patients: a cross-sectional study in a tertiary healthcare facility in Ghana. BMC Psychiatry. 2018;18(1): 17 